The efficacy of (+)-4-propyl-9-hydroxynaphthoxazine as adjunctive therapy in Parkinson's disease

Ther 1984;230:569-76.

2 Stoessl AJ, Mak E, Calne BD. (+)-4-propyl-9hydroxynaphthoxazine. (PHNO), a new dopaminomimetic, in treatment of parkinsonism. Lancet 1985;ii:1330-1.

3 Grandas F, Quinn N, Critchley P, Rohan A, Marsen CD, Stahl SM. Antiparkinsonian Activity of a Single Oral Dose of PHNO. Movement Disorders 1987;2:47-51.

4 Meunter MD, Ahlskog JE, Bell G, McManis P. PHNO [(+)-4-propyl-9-hydroxynaphthoxazine]: a new and effective anti-Parkinson's disease agent. Neurology 1988;38:1541-5.
5 Yebenes JG, Fahn S, Jackson-Lewis V, Mena MA. Intracerebro-ventricular infusion of $(+)-4$-propyl-9hydroxynaphthoxazine reverses the behavioural effects of dopamine deficiency in rats. Ann Neurol 1987;22:145.

6 Koller W, Herbster G, Gordon J. PHNO, a Novel Dopamine Agonist, In Animal Models of Parkinsonism. Movement Disorders 1987;2:193-9.

7 Weiner WJ, Sanchez-Ramos J, Factor SA, Hefti F. The Efficacy of 4-Propyl-9-Hydroxynaphthoxazine (PHNO) in Parkinson's Disease. Neurology 1987;37(suppl 1):276.

\title{
West's syndrome
}

In a lengthy letter to the Lancet, dated 26 January, 1841, Dr W J West of Tunbridge described “ $a$ very rare and singular species of convulsion ... the only case I have witnessed is in my own child." The child, nearly a year old, was healthy till 4 months of age, then developed bobbings of the head forwards, which

"became so frequent and powerful, as to cause a complete heaving of the head forwards towards his knees, and then immediately relaxing into the upright position, something similar to the attacks of emposthotonous: these bowings and relaxings would be repeated alternately at intervals of a few seconds and repeated from ten to twenty or more times, for two or three minutes; he sometimes has two, three or more attacks in the day . . just before they come on he is all alive and in motion, making a strange noise, and then all of a sudden down goes his head and upwards his knees; he then appears frightened and screams out. . . . A fine grown child, but he possesses neither the intellectual vivacity or the power of moving his limbs, of a child of his age . . . looks placid and pitiful, yet his hearing and vision are good; he has no power of holding himself upright or using his limbs and his head falls without support."

West describes a wide variety of (noxious) treatments he applied, in vain. He consulted Sir Charles Clarke and Dr Locock; the former had seen four cases and referred to it as salaam convulsion, the latter two cases. The cases he had ascertained had become paralytic and idiotic, dying between the ages of 17 and 19 years; one perfectly recovered. It appeared to West

"to be either due to irritation of the nervous system from teething," though Sir Astley Cooper had opined in another case 'disease of the brain and the child will not recover, or it proceeds merely from teething, and, when the child cuts all its teeth, may probably get well' ".

Thus West takes full credit for the tragic but lucid exposition of hypsarrhythmic infantile spasms, and Sir Charles Clarke for coining the apt description of "salaam convulsion", which has stood the test of time.

J M S Pearce 